its melting point for laboratory experiments. Bismuth, although brittle under certain conditions, can be extruded and, in addition, expands on freezing; the analogy with ice is therefore complete.

Mr. C. Gurney took up this point later by saying that, whereas the effect of hydrostatic pressure on the melting point is of opposite sign for ice and metals, the effect of uniaxial compression is always to lower the melting point, even in metals.

In reply to Dr. G. W. Scott Blair's suggestion that ice might be found to behave more like a Bingham solid than a material obeying St. Venant's law of plasticity, Dr. Orowan said that the existence of transient creep is evidence that ice is not a Bingham solid; on the other hand, the existence of creep in general shows that it does not exactly obey St. Venant's law either.

Dr. Perutz had observed that in Alpine glaciers the crevasses were never more than about $30 \mathrm{~m}$. deep, and Mr. W. H. Ward pointed out that this depth could be correlated in order of magnitude with the known yield stress of ice.

The discussion provided a happy illustration of the benefit of applying the simplest of physical reasoning to a science as yet largely empirical. In the words of one of the contributors, it was "better to think exactly with simplified ideas than to reason inexactly with complex ones".

J. F. NyE

\section{PROGRESS IN ARTIFICIAL ILLUMINATION}

A

LTHOUGH lip-service is commonly paid to the value of research, it is seldom that its direct benefits are so attractively displayed to the general public as has been done in the "Darkness into Daylight" Exhibition at the Science Museum, London, S.W.7. A visit to the Exhibition reminds one how very primitive were the means of artificial illumination only two centuries ago, while less than one hundred years ago the oil lamp was still the common form of lighting. We are all of us aware of the progress and achievements made during the past century. But how many realize that since only 1921 the efficiency of the ordinary 60-watt electric lamp has increased by 55 per cent while the cost has decreased by 75 per cent.

The exhibition has been organised by the Science Museum with the co-operation of the electrical industry of Britain, mainly to set forth the story of the development of electric lighting, but also to give a lead, and an example of the form of artificial illumination in the future.

A brief introductory section includes examples of some of the primitive forms of lighting used by early man-a hollow stone with fibre burning in animal fat, a wicker-work cage of fire-flies, sea-shell and oyster-shell lamps, a burning fish and a wick threaded into the body of a stormy-petrel are typical examples.

Passing from these primitive forms of lighting, a brief survey of the stages from the Middle Ages to the nineteenth century is made in a series of dioramas, showing the gradual changes brought about as candles and tallow-dipped rushes gave place to oil lamps and then in turn to the gas lamps of the last century. We can see the dawn of electric lighting with Swan's invention of 1878, its temporary eclipse by the Welsbach incandescent gas mantle and then the final triumph of the electric filament lamp.
The filament lamp has had a long career, and since its invention by Swan in 1878 and Edison in 1879 it has passed through innumerable stages of development. Swan had spent many years of research before he produced his carbon filament in 1878 and, incident. ally, he laid the foundation stone of the rayon industry by his subsequent development of the squirted nitrocellulose filament in 1883 . In stages, the carbon filament with its low efficiency of 2-3 lumens per watt gave way, first to the osmium filament, then to tantalum and finally to tungsten, when the difficulties of drawing tungsten wire had at last been overcome.

The tungsten-filament vacuum lamp had an efficiency nearly three times that of the carbon filament lamp, but to improve it still further a higher operating temperature was required. This resulted in an early blackening of the bulb, and although this could be overcome by filling the bulb with an inert gas, the heat lost by convection more than compensated for the gain until Langmuir's invention of the coiled filament in 1913. Still higher efficiencies were obtainable from the 'coiled-coil' filament invented soon after, but manufacturing difficulties prevented its introduction until 1934 .

The efficiency of the modern filament lamp varies from the order of 12 lumens per watt for the smaller domestic sizes to about 25 lumens per watt for the largest projector lamps and, regarded as a source of artificial illumination, it must be agreed that the filament lamp is a remarkably cheap device. Indeed, as the visitor to the 'Darkness into Daylight' Exhibition is reminded at one stage, the average 60 -watt lamp will burn for 1,000 hours at a cost, including that of the bulb, of only about $8 s .4 d$.; but were he by some whim or fancy to select candles as an alternative illuminant, he would need no less than 25,000 of them to give the same level of illumination for the same period and he would find himself faced with a bill of about $£ 100$ !

As is perhaps inevitable, the accent of the Exhibition is on fluorescent lighting, and as one passes through this section one is forced to wonder whether the life of the filament lamp is doomed and whether it will eventually be replaced, like the oil lamp and the gas lamp before, by the low-pressure fluorescent tubes now being so widely used. Hitherto, these fluorescent lamps have only been available in lengths of 4 and $5 \mathrm{ft}$., but the recent announcement that 2 -ft. tubes of 20 - and 40-watt ratings will soon be introduced suggests a much wider application for domestic purposes. The fluorescence section of the Exhibition opens with a brief historical account of the discovery and developments which have contributed to the perfection of the modern tubes-the early observations of fluorescence, the Becquerel lamp of 1867 in which fluorescent materials were exeited in a discharge tube, and the discovery in 1923 of a means of applying fluorescent materials to the walls of a mercury lamp. The stories of the search for a better colour spectrum, the first 'daylight' lamps and the finding of a single powder for producing a warmwhite light are told by subsequent exhibits.

In imagination one is encouraged by a variety of fluorescent exhibits to regard such lamps as the lighting of the future. For industrial and commercial applications this indeed appears inevitable, but in spite of the three-fold improvement in efficiency and in spite of the three-fold increase in the average life, it still seems likely that the higher initial installation costs will reprieve the filament lamp for many years for ordinary domestic purposes. 
In a brief review such as this, it is not possible to refer to the many stages of development in the various types of discharge lamps-the low-pressure sodium lamp with hot cathode, the low-, medium- and high-pressure mercury lamps, or to mention more than briefly the $5 \mathrm{~kW}$. high-pressure water-cooled xenon arc now being shown to the public for the first time. Many of these developments are illustrated by exhibits and are described in greater detail with diagrams and photographs in the official handbook, "Darkness into Daylight", by W. T. O'Dea, which has been published in connexion with the exhibition (London : H.M. Stationery Office. 1s.).

The exhibition will remain open until September from 10 a.m. until 6 p.m. daily, and from 2.30 p.m. until 6 p.m. on Sundays; admission is free at all times.

\section{PLANKTONIC COPEPODS AND HYDROCORALS OF THE JOHN MURRAY EXPEDITION}

\footnotetext{
OOLONEL SEYMOUR SEWELL'S account* of 4 a large collection of free-swimming copepods from the Indian Ocean is an important critical study and a most valuable contribution to our knowledge of copepods in general.

In a previous paper (Sewell, 1920-32), seventeen species of free-swimming planktonic copepods were recorded from the northern part of the Indian Ocean, which up to that time were not known from any region other than the Atlantic Ocean or the Atlantic section of the Antarctic. The present collection contains twenty-one other species that so far have not been recorded beyond the Atlantic Ocean. As the author remarks, such a comparatively large number of deep-sea species that are common to the Atlantic and the Indian Ocean, but are at present unknown from any other region, indicates that there either is or has been a close connexion between the two regions. He has suggested (Sewell, 1940) that the explanation is to be found in the trend of the deep currents of the present day. He promises to deal later with the geographical distribution.

Well over two hundred species are recorded, with notes and remarks on most of them which are interesting and instructive. The new family Megacalanidæ is formed to include Megacalanus, Bathy calanus and Brachycalanus, all of which differ from the Calanidæ in several features and show a corresponding resemblance to the Centropagidæ.

Only one specimen of Calanus finmarchicus was found, a male, from the northern area of the Arabian Sea, 1,500-0 metres. It is rare in the Indian Ocean and it is suggested that its presence is explained by individuals being carried from the Atlantic Ocean round the Cape of Good Hope in the North Atlantic intermediate waters or the West Wind Drift, and then that they are caught up in the Sub-Polar Intermediate Current and so are carried northwards into the Arabian Sea.

Among the Sapphirinas it was found that Sapphirina iris was associated with the aggregated form of the salp Pegea confederata, some being inside. In this

- The Free-Swimming Planktonic Copepoda : Systematic Account. By Lieut.-Colonel R. B. Seymour Sewell. (The John Murray Expedition, 1933-34, Scientific Reports, Vol. 8, No. 1.) Pp. 304. (London : British Museum (Natural History), 1947.) 308 .
}

genus there were numerous cutaneous glands, opening on both dorsal and ventral aspects of the body in special positions in the different species. It is tempting to regard these as luminous organs, but the author does not wish to express an opinion on this point.

There is a long list of copepods with parasites both from surface-living and deep-dwelling species. This includes twenty-one species infested with the dino. flagellate Blastodinium. Comparing these with Chatton's seventeen species from the Mediterranean infested with Blastodinium, it is found that six are common to both lists.

Dr. Hjalmar Broch has found three new species in the four hydrocorals brought home by the John Murray Expedition to the Indian Ocean*. These include two new stylasters ( $S$. (Eustylaster) ramosus and S. (Eustylaster) lonchitis), and one new Crypthelia (C. clausa), the fourth species being Crypthelia stenopoma Hickson and England. The two stylasters were from the Pemba Canal and the Crypthelia from the Maldives. It is interesting to note that in neither of these localities have Stylasteridæ been found before, and these reported localities of the John Murray Expedition are at the present day the most northerly localities of the Western Indian Ocean from which Stylasteridæ have as yet been found.

Another very interesting point is that whereas the two Stylaster species from the Pemba Canal have been collected in that zone of the bathymetrical region where the genus is known to be comparatively abundant in all seas, the localities of Crypthelia at the Maldives belong to the uppermost parts of its habitat, and its occurrence in these depths seems to be very scanty. The depth of 229 metres is the shallowest record of the genus, and Crypthelia stenopoma has hitherto only been taken in 1,300 metres or deeper in the Indo-Malayan Sea. Stylaster ramosus was abundant in two stations, its structure indicating that, like Crypthelia stenopoma and other Stylasteridæ, it is probably inhabited by commensal polychætes. The cirripede, Pyrgoma, is also com. monly found in it.

- Stylasteridm (Hydrocorals) of the John Murray Expedition to the Indian Ocean. By Dr. Hjalmar Broch. (The John Murray Expedition, 1933-34, Scientific Reports, Vol. 8, No. 2.) Pp. 305-361 +1 plate. (London: British Museum (Natural History), 1947.) 28. $6 \bar{d}$.

\section{THE ELECTRICITY GRID IN GREAT BRITAIN}

$T$ HE twentieth and last annual report of the Central Electricity Board has recently been published (Whitehead Morris, Ltd., 72-78 Fleet Street, London, E.C.4. $\quad$ ls. net). Just short of attaining its majority, the Board loses its identity in the infant British Electricity Authority, this sturdy infant in. heriting the Grid system of some 150 generating stations, capable of an output of nearly 12 million kilowatts. Appropriately appearing at about the same time as this report is an interesting and informative paper dealing with the British grid system ("Load Dispatching and the British Grid System"A. R. Cooper, Institution of Electrical Engineers, March 18, 1948), a paper which is wider in scope than its title might suggest.

Mr. Cooper describes first the long-term planning associated with the extension of such a system; planning which, as the Central Electricity Board report makes clear, has had to yield to some extent 